\title{
Simulating the Transport and Fate of Trifuralin in Soil
}

\author{
Ying Ouyang ${ }^{1 *}$, Jia-En Zhang ${ }^{2}$, Li Hua Cui ${ }^{3}$, and Peter Nkedi-Kizza ${ }^{4}$
}

${ }^{1}$ USDA Forest Service, 100 Stone Blvd, Thomson Hall, Room 309, Mississippi State, MS 39762, USA; ${ }^{2}$ Department of Ecology, College of Agriculture, South China Agricultural University, 510642 Guangzhou, China; ${ }^{3}$ Department of Environmental Science and Engineering, South China Agricultural University, Guangzhou 510642, China; ${ }^{4}$ Department of Soil and Water Sciences, University of Florida, Gainesville, FL 32611 , USA

Received: January 6, 2012 / Accepted: February 27, 2012

\begin{abstract}
Understanding herbicide dynamics in agricultural soils is crucial to evaluate herbicide application efficiency and its environmental consequences. A model for herbicide trifluralin ( $\alpha, \alpha, \alpha$-reifluoro-2,6-dinitro- $\mathrm{N}, \mathrm{N}$-dipropyl-płolvidine) dynamics namely runoff, erosion, leaching, volatilization, and degradation losses in agricultural soils was developed using the software package Structural Thinking and Experiential Learning Laboratory with Animation (STELLA ${ }^{\mathrm{TM}}$ ). The model was calibrated using field data with a good agreement between model predictions and field measurements before its applications. A simulation scenario was then performed to predict trifluralin dynamics in a $\mathbf{1 . 2 6}$ ha soybean field. Simulation results showed that in general, the rate of water runoff decreased with the rate of rainfall; however, the rates of trifluralin and sediment losses in runoff depended not only on the rate of rainfall but also on the content of trifluraline in the liquid and solid phases. The rates of trifluralin leaching and volatilization decreased sharply within the first couple of days following the surface spray of trifluralin due to its strong adsorption and soil incorporation. Simulation results further revealed that the rate of trifluralin degradation in the soil decreased exponentially with time. About $6 \%$ of the total applied trifluralin remained in the soil at the end of the simulation period (120 days). This study suggests that the model, developed with STELLA ${ }^{\text {TM }}$, is a useful fool for estimating herbicide dynamics in agricultural soils.

Keywords: Degradation, Model, Leaching, Runoff, Herbicide, Soil, STELLA, Volatilization.
\end{abstract}

\section{Introduction}

Millions of kilograms of herbicides are intentionally applied into soils each year to control weeds. To be most effective, efficient, and environmentally favorable, however, herbicides should remain within the targeted surface soil. Unfortunately, numerous herbicides do not remain entirely in the root zone (USEPA, 1987). These toxic herbicides leach and runoff from agricultural fields and lawn yards, presenting serious problems for contaminating soil and water resources in ecosystems.

The emergence of herbicide-related issues involving water quality and potential impacts on non-target species have stimulated much interest in characterizing the environmental fate of herbicides in agricultural ecosystems. Over the last decades, many researchers have investigated the behavior and fate of herbicides in the root zone, the factors contributing to their leaching in soils, and the potential for contamination of surface water and groundwater (Nofziger and Hornsby, 1986; Carsel et al. 1988; Kookana et al. 1992; Green et al. 1995; Di and Aylmore, 1997; Ouyang and Mansell, 1999; Ouyang et al., 2003 and 2005). These investigations have shown that herbicide solubility, sorptive property, volatility, formulation, and organic carbon content predominantly determine the fate and tendency of herbicides to runoff and leach through soils (Ouyang and Mansell, 1999). Other important influencing environmental and agricultural factors include soil properties, climatic conditions, crop types, and cropping practices.

A variety of mathematical models have been developed to investigate the fate and transport of herbicides in agricultural land (Foussereau et al., 1993). Some of the models used to estimate herbicide movement in surface and subsurface environ-

\footnotetext{
* Corresponding author: youyang@fs.fed.us
} 
ments include PRZM-2 (Mullins et al., 1993), LEACHM (Hutson and Wagenet, 1992), and GLEAMS (Knisel, 1993). Application of these models has improved our understanding of the fate and transport of herbicides in agricultural ecosystems. One limitation for most of these models, however, is that the values of most of the required input parameters are not exact and represent some uncertainties. These input parameters are difficult to obtain through experimental measurements for model calibrations, validations, and applications. Therefore, a need exists to develop a novel and yet a realistic modeling tool that can be easily used for effective investigations of herbicide dynamics in agricultural ecosystems.

The purpose of this study was to construct a dynamic model for herbicides in agricultural soil, using the commercial available package STELLA (Structural Thinking and Experiential Learning Laboratory with Animation). STELLA is a modeling tool for building a dynamic modeling system by creating a pictorial diagram of a system and then assigning the appropriate values and mathematical functions to the system (Isee Systems, 2006). A brief overview of STELLA is given in the Materials and Methods section. Specific objectives of this study were to: i) develop a dynamic model for predicting runoff, leaching, volatilization, and degradation of herbicides in agricultural soils; ii) calibrate the model using available experimental data; and iii) apply the model to predic herbicide trifluralin dynamics in a soybean field.

\section{Materials and Methods}

\section{STELLA Overview}

STELLA is a user-friendly commercial software package for building dynamic modeling systems. It uses an iconographic interface to facilitate the construction of dynamic system models. The key features of STELLA consist of the following four tools: (1) stocks, which are the state variables for accumulations; they collect whatever flows into and out of them; (2) flows, which are the exchange variables, they control the arrival or the exchanges of information between the state variables; (3) converters, which are the auxiliary variables; these variables can be represented by constant values or by values depending on other variables, which are curves or functions of various categories; and (4) connectors, which are to connect among modeling features, variables, and elements. STELLA offers a practical way to dynamically visualize and communicate how complex systems and ideas really work (Isee Systems, 2006). STELLA has been widely used in biological, ecological, and environmental sciences (Hannon and Ruth, 1994; Peterson and Richmond, 1996; Costanza et al., 2002; Aassine and El Jai, 2002; Ouyang, 2008). An elaborate description of STELLA package can be found in ISEE Systems (2006).

\section{Model Development}

A schematic diagram for herbicide dynamics in agricultural lands pertaining to this study is shown in Fig. 1. This diagram shows the following seven major procedures and mechanisms of an herbicide: (1) application to foliage and soil; (2) wash off from foliage; (3) loss from surface runoff and soil erosion; (4) volatilization; (5) uptake by roots; (6) sorption and degradation; and (7) leaching. These mechanisms are highly coupled with soil water movement. Therefore, when modeling the herbicide dynamics in agricultural land, soil water movement must be considered. Detailed descriptions of each mechanism or process for water movement and herbicide dynamics are presented below, while the input values for coefficients and constants in the following equations are provided in Table 1.

\section{Soil Water Dynamics}

Soil water dynamics involve runoff, percolation, rainfall/irrigation, and evapotranspiration (Fig. 1B). The surface water runoff $\left(\mathrm{cm} \mathrm{d}^{-1}\right)$ is estimated using the curve number method as follows (Mullins et al., 1993):

$$
\text { Runoff }=\frac{(R I-0.2 S)^{2}}{(R I+0.8 S)}
$$

where $\mathrm{RI}$ is the rainfall and/or irrigation $\left(\mathrm{cm} \mathrm{d}^{-1}\right)$ and $\mathrm{S}$, the watershed retention parameter, is estimated by:

$$
S=\frac{1000}{C N}-10
$$

where $\mathrm{CN}$ is the runoff curve number. The value of a curve numbers is a function of soil type, soil physical properties, crop type, and management practices. Surface water runoff occurs only when rainfall and/or irrigation rate exceeds the infiltration capacity of the soil. Surface water runoff rate can also be estimated from direct measurements.

The soil water percolation rate $\left(\mathrm{cm}^{3} \mathrm{~d}^{-1}\right)$ is estimated by the following equation (Mullins et al., 1993):

$$
\text { Percolation }=\alpha\left(\theta-f_{c}\right)
$$

where $\alpha$ is the drainage coefficient ( $\mathrm{cm} \mathrm{d}-1), \Theta$ is the volumetric water content $\left(\mathrm{cm}^{-3} \mathrm{~cm}^{-3}\right)$, and $f$ is the field water capacity $\left(\mathrm{cm}^{-3}\right.$ $\mathrm{cm}^{-3}$ ). The evapotranspiration (ET) can be estimated by PenmanMonteith model, Priestley-Taylor equation, or evaporation pan method.

\section{Soil Herbicide Dynamics}

Soil herbicide dynamics include: i) solid phase loss due to soil erosion; ii) liquid phase runoff loss from soil surface and leaching into the deeper soil profile; iii) adsorption by soils which is predominantly due to soil organic matter; iv) degradation by soil microorganisms; v) uptake by plant roots; vi) application to the soil surface or wash off from plant foliage; and vii) volatilization into the atmosphere (Fig. 1C). The soil erosion loss is estimated with the Universal Soil Loss Equation (USLE) as follows (Wischmeier and Smith, 1978):

Soil Erosion Loss Rate $=$ At $(R K L S C P)$ 
where $A$ is the surface area, $t$ is the time, $R$ is the rainfall erodibility factor, $K$ is the soil erodibility factor, $L S$ is the length-slope factor, $C$ is the soil cover factor, and $P$ is the soil conservation factor.

The herbicide erosion loss $\left(\mathrm{mg} \mathrm{d}^{-1}\right)$ can be, therefore, estimated as:

Pesticide Erosion Loss $=\frac{\text { Soil Erosion Loss Rate }{ }^{*} \text { Mass }_{\text {solid }}}{\text { Soil Volume }^{*} \text { Bulk Density }}$

where $M_{\text {solid }}$ is the mass of herbicide in the solid phase (mg). The herbicide leaching loss ( $\mathrm{mg} \mathrm{d}^{-1}$ ) is estimated as follows:

Pesticide Leaching Loss $=$ Total Percolation $* \mathrm{C}_{\mathrm{w}}$

where $C_{w}$ is the concentration of herbicide in the liquid phase. The herbicide runoff loss $\left(\mathrm{mg} \mathrm{d}^{-1}\right)$ is given as:

Pesticide Runoff Loss $=$ Total Water Runoff $* \mathrm{C}_{\mathrm{w}}$

Other processes such as the rates of herbicide plant uptake, degradation, sorption, and volatilization are dependent on the properties of plant species, soil, and herbicide and should be obtained from experimental measurements.

\section{STELLA Model Structure}

The first step in modeling processes was to develop a basic structure to capture the processes described above using STELLA.
In Fig. 2, the rectangles are stocks that graphically represent the volume of water or the mass of herbicides in the solid, liquid, and vapor phases. The flow symbols (represented by double lines with arrows and switches) represent the rates of water or herbicide flow into or out of the stocks. The other variables are converters (represented by empty circles) that denote the rules or conditions controlling the stocks and flows through the use of connectors (represented by single lines with arrows).

Water leaves the soil through percolation that is controlled by surface area, field capacity, and drainage coefficient; through evapotranspiration (ET) that is governed by soil surface area and ET coefficient; and through surface runoff that is constrained by surface area and runoff coefficient (Fig. 2). Water can also enter the soil as rainfall and/or irrigation. Similar transport mechanisms occur for soil herbicides as shown in Fig. 2. These mechanisms can be quantified in the model through Eqs. (4) to (7). In addition, soil herbicide concentration is obtained using the following equation:

$$
C_{w}=\frac{m_{\text {soil }}^{\text {cont }}}{V_{s w}}
$$

where $m_{\text {soil }}^{\text {cont }}$ is the total soil herbicide mass $(\mathrm{mg})$ in liquid phase and $V_{s w}$ is the volume of soil water $\left(\mathrm{cm}^{3}\right)$.

After the basic structure was developed, the second step was to assign the initial values for stocks, equations for flows, and input values for converters. For example, the soil erosion loss (represented by empty circle as shown at the bottom of Fig. 2) was calculated using soil cover, erodibility, rainfall erodibility, slope length, and soil conservation factors through Eq. (4).

Table 1. Input parameter values used for model calibrations.

\begin{tabular}{|c|c|c|}
\hline Parameter & Value & Reference \\
\hline \multicolumn{3}{|l|}{ Water Dynamics } \\
\hline Curve number & 81 & Nearing et al., 1996 \\
\hline Rainfall & Varied & White et al., 1977 \\
\hline Soil area $\left(\mathrm{cm}^{2}\right)$ & $12 \times 10^{7}$ & White et al., 1977 \\
\hline Soil depth $(\mathrm{cm})$ & 7.5 & White et al., 1977 \\
\hline Field capacity & 0.3 & Estimated from White et al., 1977 \\
\hline Drainage coefficient (cm/day) & 0.025 & Nearing et al., 1996 \\
\hline Initial soil water content $\left(\mathrm{cm}^{3} / \mathrm{cm}^{3}\right)$ & 0.27 & Estimated from White et al., 1977 \\
\hline Evapotranspiration (cm/day) & 0.0059 & Estimated from White et al., 1977 \\
\hline Rainfall erodibility factor & 300 & Maidment, 1993 \\
\hline Runoff coefficient & 0.015 & Estimated from White et al., 1977 \\
\hline Slope length factor & 0.8 & Maidment, 1993 \\
\hline Soil conservation factor & 0.25 & Maidment, 1993 \\
\hline Erodibility factor & 0.12 & Maidment, 1993 \\
\hline Soil cover factor & 0.0005 & Maidment, 1993 \\
\hline Bulk density $\left(\mathrm{g} / \mathrm{cm}^{3}\right)$ & 1.6 & Hetrick and Travis, 1988 \\
\hline \multicolumn{3}{|l|}{ Herbicide Dynamics } \\
\hline Herbicide application rate $\left(\mathrm{mg} / \mathrm{cm}^{2}\right)$ & 0.01 & White et al., 1977 \\
\hline Foliar pest. wash off rate $\left(\mathrm{mg} / \mathrm{cm}^{2}\right)$ & 0 & White et al., 1977 \\
\hline Herbicide degradation rate $(\mathrm{mg} / \mathrm{d}$ ) & 0.0206 & Mullins et al., 1993 \\
\hline Herbicide volatilization rate $(\mathrm{mg} / \mathrm{d})$ & Varied & White et al., 1977 \\
\hline Herbicide uptake rate $(\mathrm{mg} / \mathrm{d})$ & 0.002 & Boersma et al., 1991 \\
\hline Herbicide sorption rate ( $1 / d)$ & 0.000073 & White et al., 1977 \\
\hline Initial soil herbicide conc. $\left(\mathrm{mg} / \mathrm{cm}^{3}\right)$ & 0 & \\
\hline
\end{tabular}



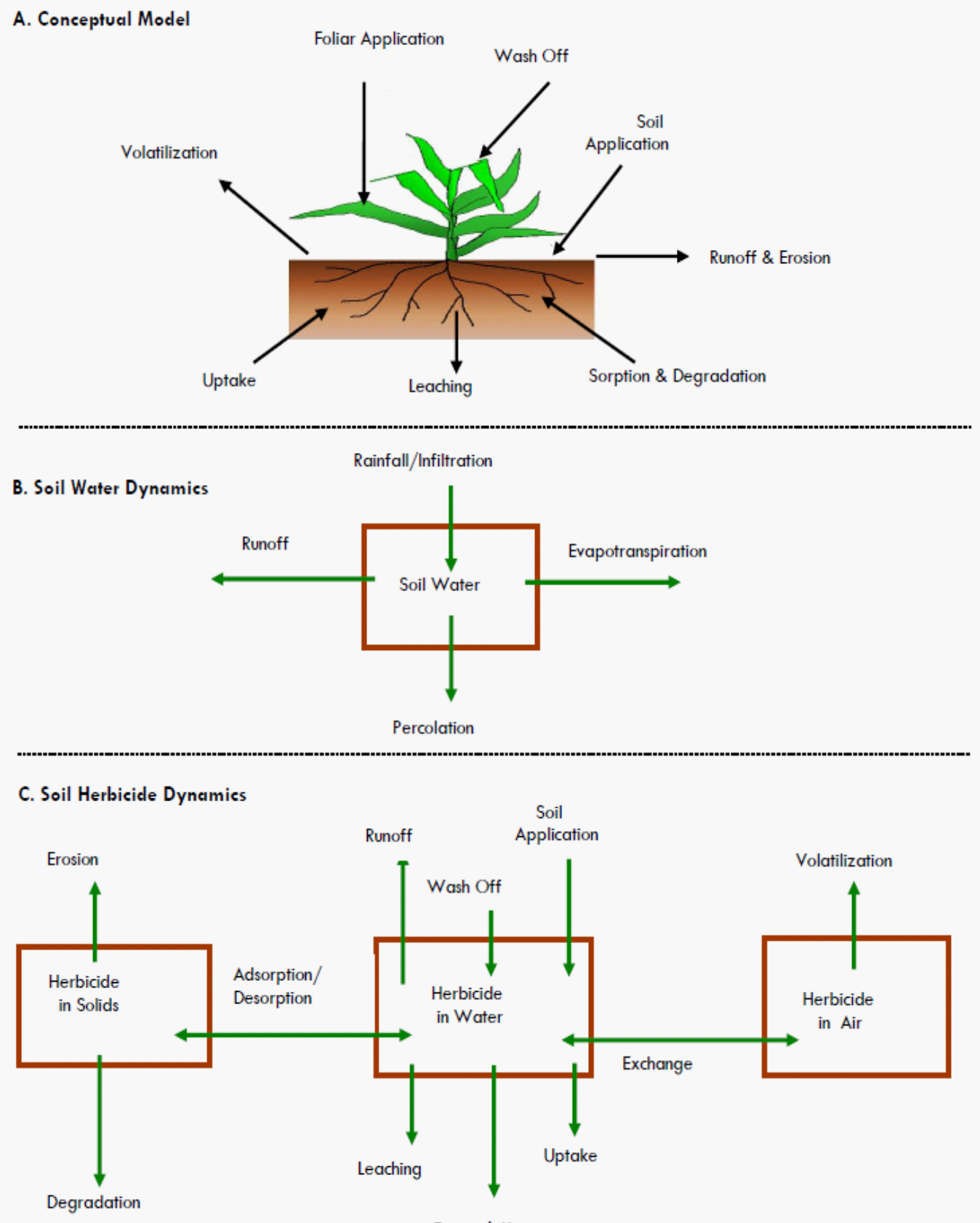

Degradation

Figure 1. A schematic diagram showing water and herbicide dynamics in agricultural soils.

\section{Results and Discussion}

\section{Model Calibration}

Model calibration is a process of adjusting input parameters within a reasonable range to obtain a match between field observations and model predictions. In this study, the model was calibrated using the experimental data reported by White et al. (1977). These authors studied trifluralin $(\alpha, \alpha, \alpha$-reifluoro2,6-dinitro-N,N-dipropyl- $\rho$ tolvidine) volatilization losses from a soybean field at Watkinsville, GA, USA. This 1.26-ha soybean research field comprised of Cecil soil with $63.35 \%$ sand, $23.6 \%$ silt, $12.5 \%$ clay, and $0.55 \%$ organic carbon; a $\mathrm{pH}$ of 6.5 ; a slope of $3.0 \%$; and trifluralin KOC of 3750 to 9253 (Hiller et al., 2008). Trifluralin was surface-applied as a spray to the bare soil surface, using a ground sprayer equipped with flat-fan nozzles, at a rate of $1.12 \mathrm{~kg} / \mathrm{ha}$. After application, the herbicide was incorporated in the surface soil with a contra-rotating tiller to a depth of $7.5 \mathrm{~cm}$, and soybean (Glycine $\max$ (L.) Merr) was planted. Air and soil samples were collected for duration of 120 days and were analyzed for trifluralin contents.

A comparison of measured and predicted trifluralin masses (in percentage) in the soil is shown in Fig. 3. The percentages were obtained by dividing the trifluralin mass at each time in- 


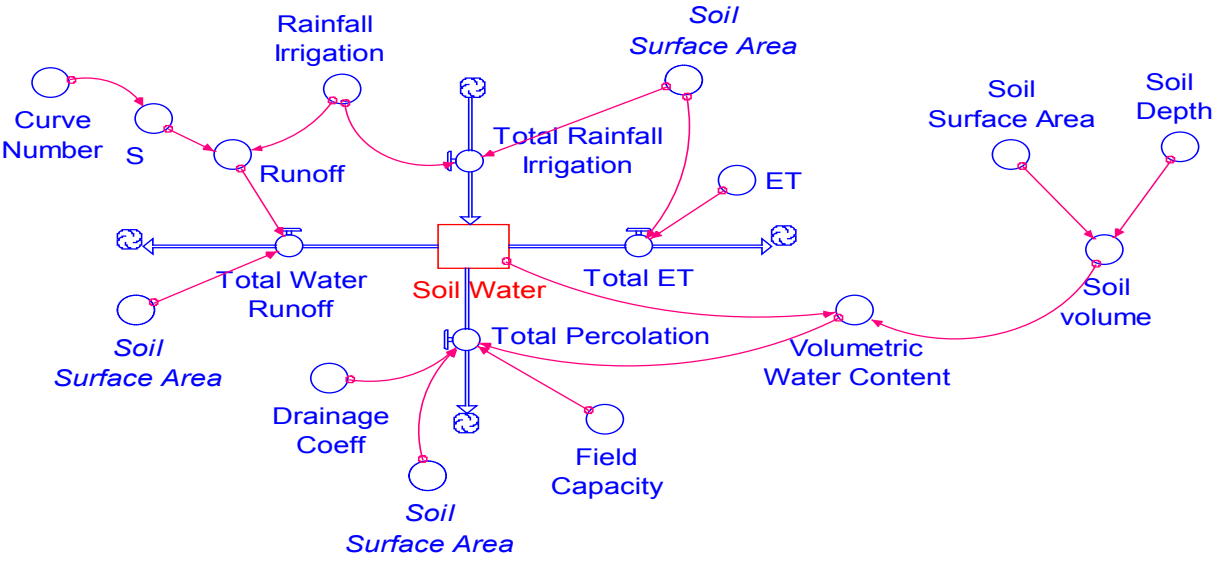

Pesticide Dynamic Model

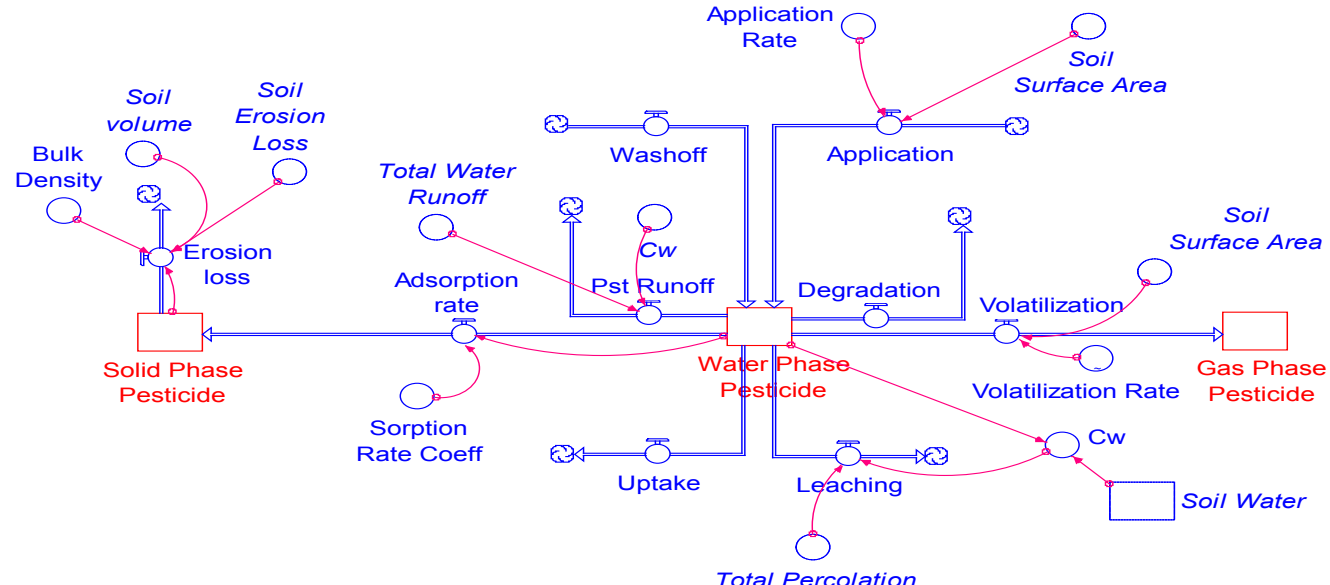

Total Percolation

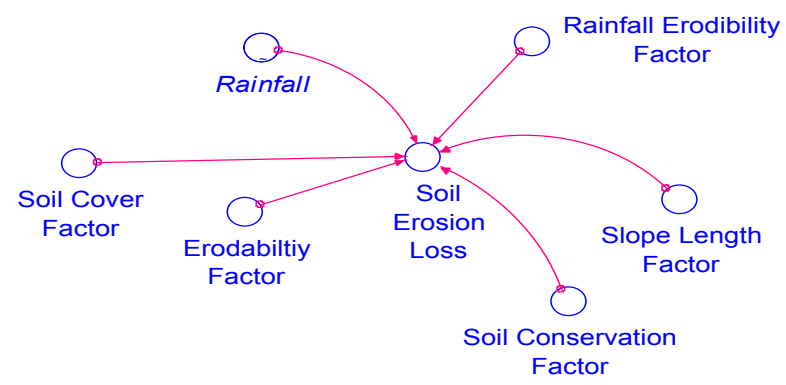

Figure 2. Soil water and herbicide dynamic model developed with STELLA.

terval of the experiment or simulation ( 120 days) by the initial trifluralin mass applied to the soil. The regression equation of the trifluralin's predicted concentration as a function of its corresponding measured concentration is as follows: $Y_{\text {prediction }}=$ $1.078 X_{\text {Measurement }}$ and $R^{2}=0.952$. This represents a very good agreement between the model predictions and the experimental measurements.

\section{Simulations}

A simulation scenario was performed to investigate water and trifluralin dynamics in the aforementioned 1.26 ha soybean field used in the model calibration. These dynamics include i) surface water runoff, percolation, and evapotranspiration; ii) trifluralin runoff, leaching, degradation, and volatilization; and iii) trifluralin mass balance. The simulation started at day 0 and lasted 120 days. Table 1 lists the values of the input parameters for the simulation conditions used in this study. It should be noted that all of the input values were directly quantified from the field data reported by White et al. (1977) or indirectly from other authors who have estimated the input values based on the same dataset reported by White et al. (1977). One exception was the uptake rate of trifluralin by soybean, which was estimated based on Boersma et al. (1991). These authors studied a ge- 


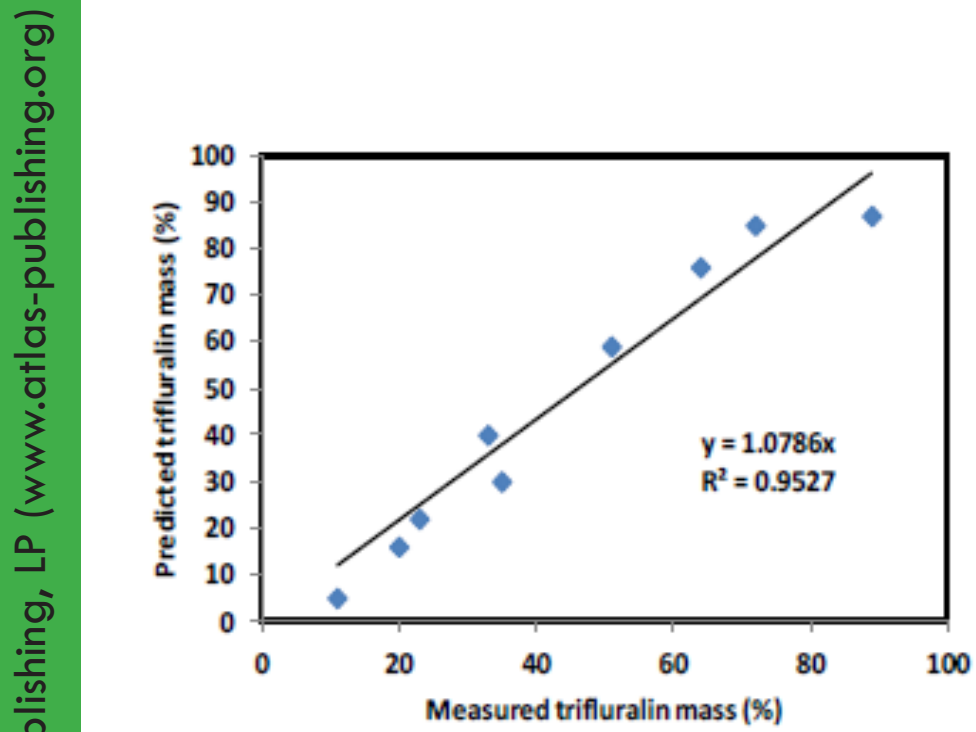

Figure 3. Comparison of predicted and measured trifluralin mass in the soil.
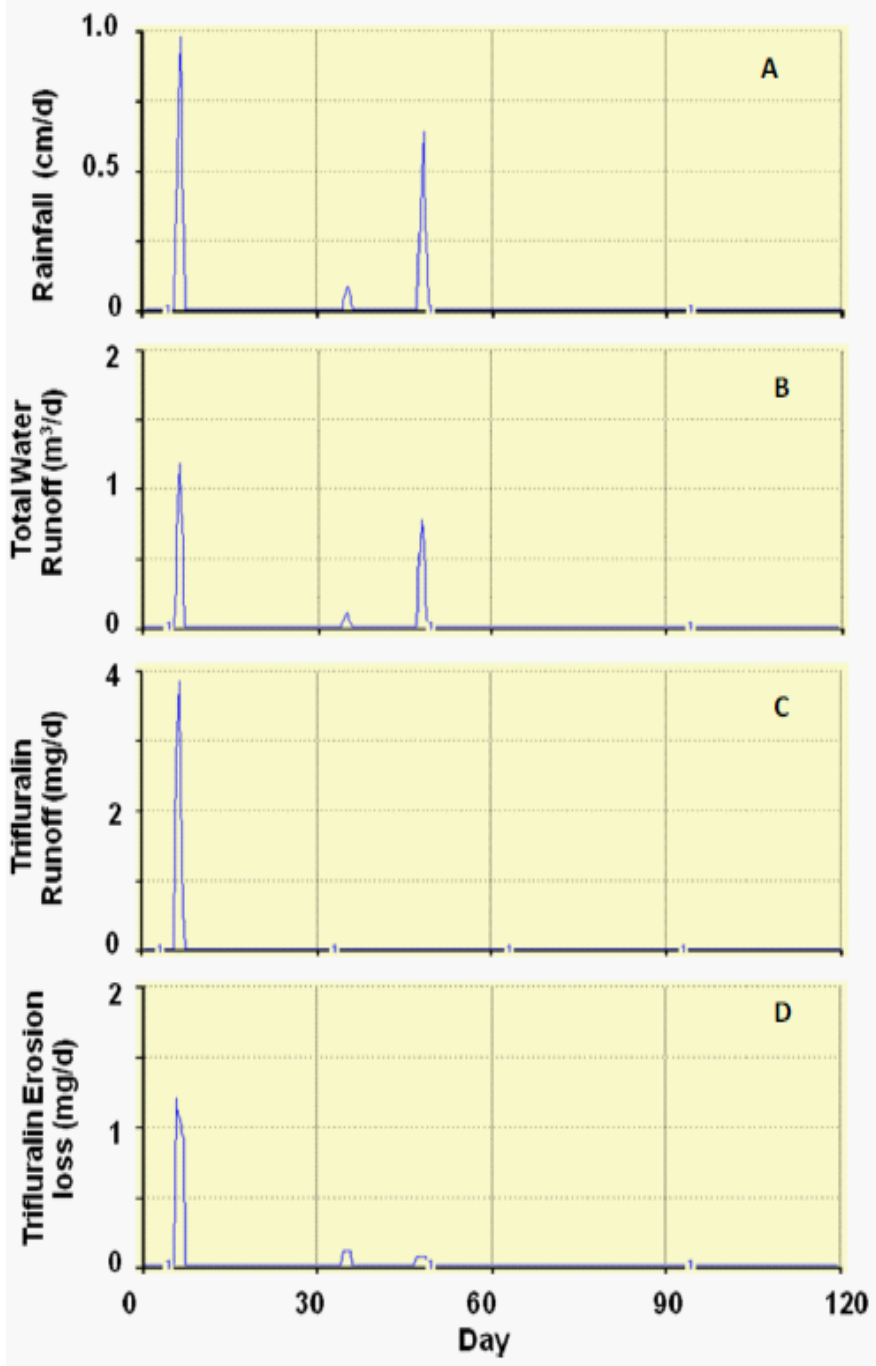

Figure 4. Rainfall (A), runoff of water (B) and trifluralin (C), and erosion of trifluralin (D) as a function of time. neric chemical uptake by soybean plants in an agricultural soil.

\section{Trifluralin Dynamics}

Rates of measured rainfall, simulated water and trifluralin runoff, and simulated trifluralin erosion loss from the soybean field are shown in Fig. 4. Overall, the rate of water runoff decreased with the rainfall rate. For example, the maximum rate of surface water runoff decreased from $1.2 \mathrm{~m}^{3} \mathrm{~d}^{-1}$ at Day 6 to $0.75 \mathrm{~m}^{3} \mathrm{~d}^{-1}$ at Day 48 as the maximum rate of rainfall declined from 0.98 to $0.64 \mathrm{~cm} \mathrm{~d}^{-1}$. However, the rates of trifluralin runoff and erosion loss depended not only on the rate of rainfall but also on the soil content of trifluralin as dissolved in the soil solution and adsorbed to the solid phase. For instance, large amounts of trifluralin erosion loss and runoff occurred during the first rainfall event at Day 6, whereas little to no trifluralin erosion and runoff were observed during the third rainfall event at Day 48. This occurred because large amounts of trifluralin were available for surface runoff and erosion loss at the first rainfall event, which was within the first week of trifluralin application to the soil. As the time elapsed after the trifluralin application, most trifluralin was strongly adsorbed by the soil and was subject to degradation by micro-organisms as well as to volatilization into the atmosphere (Parr and Smith, 1973; White et al.,
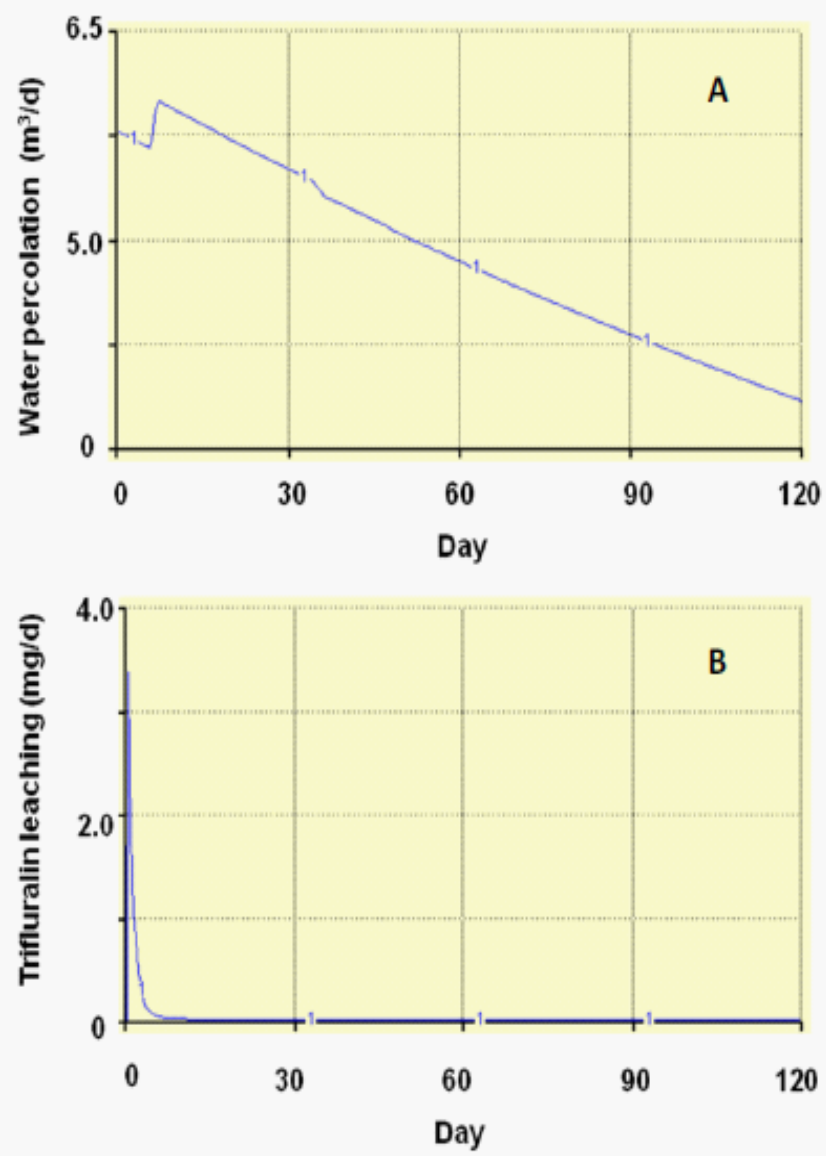

Figure 5. Soil water percolation (A) and trifluralin leaching (B) as a function of time. 
1977). As a result, little to no trifluralin runoff and erosion losses were found during the third rainfall event at Day 48.

Excess soil water percolation and trifluralin leaching into a deeper soil profile should be evaluated in conjunction with soil water percolation (Fig. 5). The rate of excess water percolation decreased after reaching a maximum rate of $6.2 \mathrm{~m}^{3} \mathrm{~d}^{-1}$ as a result of the first rainfall event at Day 6. In contrast, most of the trifluralin leaching occurred within the first two days after the trifluralin application (Fig. 5). This occurred because trifluralin was strongly adsorbed by the soil particles after its application and consequently did not leach (Fig. 7).

The rate of trifluralin volatilization decreased sharply within the first couple of days after trifluralin application and incorporation (Fig. 6). The maximum volatilization rate of trifluralin was $0.18 \mathrm{mg} \mathrm{d}-1$ at Day 1 and near zero in about two weeks. A similar finding was reported by White et al. (1977). The volatilization rate of trifluralin decreased primarily because the surface applied trifluralin was incorporated into the soil.

The rate of trifluralin degradation in the soil showed an exponential decrease as time elapsed. The rate of trifluralin degradation reached a maximum of $0.18 \mathrm{mg} \mathrm{d}^{-1}$ on Day 1 when the trifluralin was applied to the soil; its minimum value was $0.02 \mathrm{mg}$ $\mathrm{d}^{-1}$ at the end of the simulation period (120 days). The rate of the trifluralin degradation was proportional to the total content
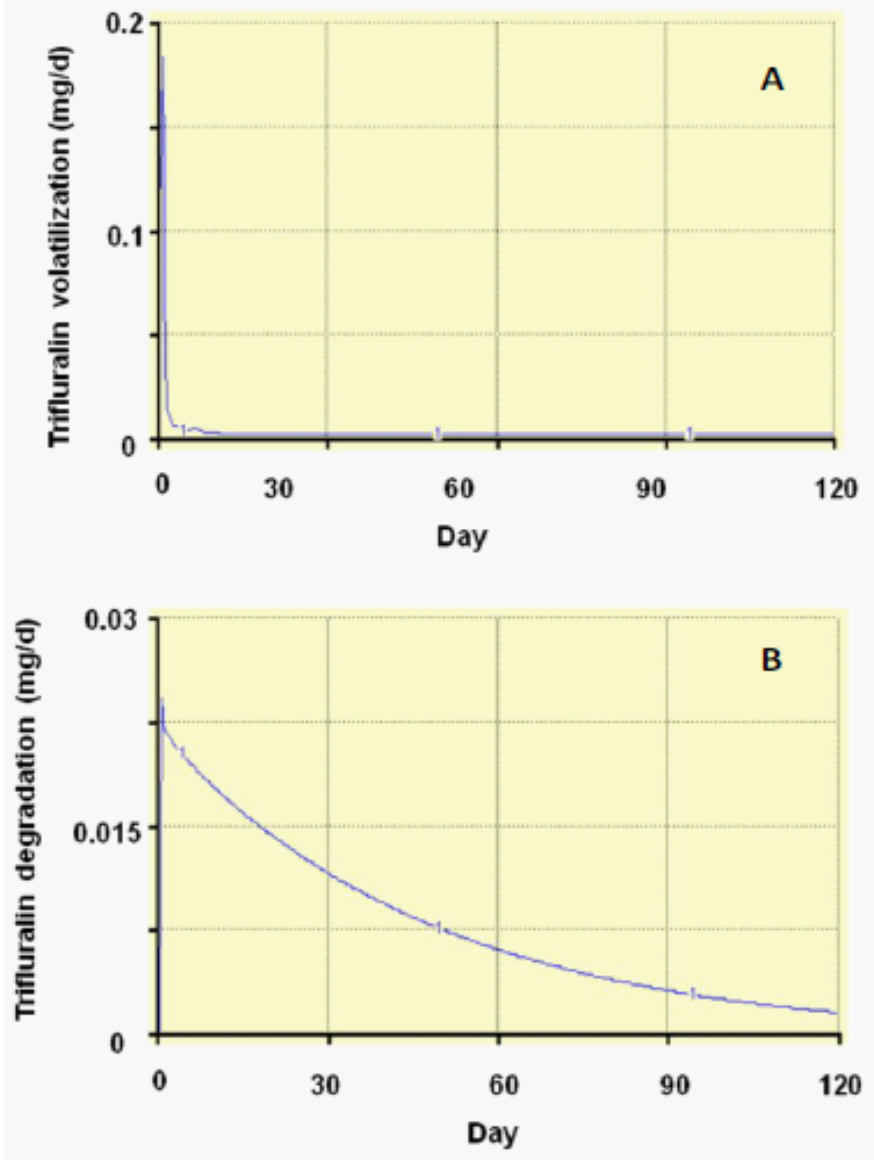

Figure 6. Trifluralin volatilization (A) and degradation (B) as a function of time.

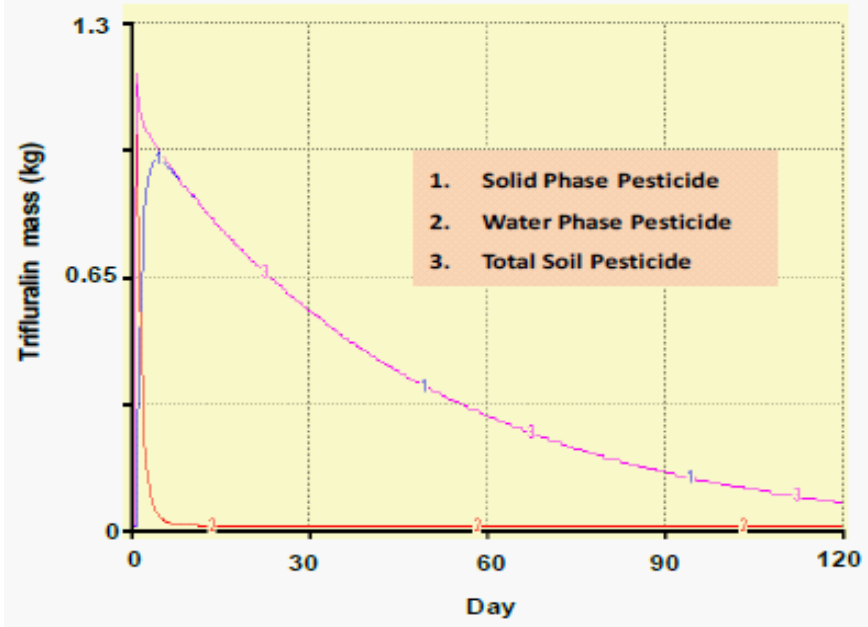

Figure 7. Trifluralin mass in soil as a function of time.

of trifluralin in the soil (Fig 7). It is clear that almost the entire mass of trifluralin was adsorbed by the soil after excess leaching and volatilization were significantly reduced 2 to 3 days after trifluralin surface application and incorporation.

\section{Trifluralin Mass}

The mass of trifluralin in the liquid phase declined sharply within the first week after its application, whereas the mass of trifluralin in the solid phase decreased exponentially with time (Fig. 7). The decline of trifluralin mass in the liquid phase occurred primarily because of the immediate adsorption of trifluralin by the soils in addition to leaching, volatilization, and root uptake. The exponential decrease of trifluralin in the solid phase was attributed to its degradation, erosion, and volatilization.

The mass balance estimation of trifluralin revealed that from the initial trifluralin mass of $1.2 \mathrm{~kg} \mathrm{ha}^{-1}$ applied to the soil, there was about $6 \%$ of trifluralin remained in the soil at the end of the simulation period ( 120 days). This simulated trifluralin remaining in the soils was lower than the $11 \%$ reported by White et al. (1977). However, $5 \%$ discrepancy (1 1\% -6\% = 5\%) between experimental data and model predictions is reasonable for modeling contaminant dynamics in the field with many unknowns. This discrepancy could be due to errors in the experimental measurement and/or values of the input parameter of the model such as the uptake of trifluralin by soybean. There was not any experimental value available in the literature for trifluralin uptake. This value was obtained based from Boersma et al. (1991). These authors simulated the uptake of a generic chemical by a soybean plant.

\section{Summary}

In this study, a model for water flow and fate of herbicides in agricultural soil was developed using STELLA ${ }^{\text {TM }}$. The simulated processes are surface water runoff, herbicide losses in surface runoff; and soil erosion. They also include herbicide leaching below the root zone, volatilization, sorption, degradation, and 
plant uptake. The model was calibrated using published experimental data. There was a good agreement between the model predictions and the measured experimental data. A simulation scenario was then simulated to demonstrate the trifluralin dynamics in a soybean field for a simulation period of 120 days. Our study reveals that the model is a useful tool for estimating herbicide dynamics in agricultural soils. Although the model was used to simulate trifluralin dynamics in a soybean field, it could be easily adapted to simulate other contaminants (e.g., other organics, metals, and nutrients) with different plant species and soil types.

\section{References}

Aassine S and MC El Jai (2002) Vegetation dynamics modelling: A method for coupling local and space dynamics. Ecolog. Modelling 154: 237-249.

Boersma L, FT Lindstrom, and SW Childs (1991) Model for steady state coupled transport in xylem and phloem. Agron. J. 83: 401-408.

Carsel RF, RS Parrish, RL Jones, JL Hansen, and RL Lamb (1988) Characterizing the uncertainty of pesticides leaching in agricultural soils. J. Contam. Hydrol. 2: 11-124.

Costanza R, A Voinov, R Boumans, T Maxwell, F Villa, H Voinov, and $L$ Wainger (2002) Integrated ecological economic modeling of the Patuxent river watershed, Maryland. Ecolog. Monographs 72: 203-231.

Di HJ, and LAG Aylmore (1997) Modeling the probabilities of groundwater contaminant by pesticides. Soil Sci. Soc. Am. 61: 17-23.

Foussereau X, AG Hornsby, and RB Brown (1993) Accounting for variability within map unit linking a pesticide fate model to soil survey. Geoderma 60: 257-276.

Green JD, R Horton, JL Baker (1995) Crop residue effects on the leaching of surface-applied chemicals. J. Environ. Qual. 24:343-351.

Hannon B, and M Ruth (1994) Dynamic Modeling. Springer-Verlag, New York.

Hetrick DM, and CC Travis (1988) Model predictions of watershed erosion components. Water Resour. Bull. 24: 413-419.

Hiller E, Z Krascsenits, and S Cernansk (2008) Sorption of Acetochlor, Atrazine, 2,4-D, Chlorotoluron, MCPA, and Trifluralin in Six Soils from Slovakia. Bull Environ. Contam. Toxicol. 80: 412-416.

Hutson Jl, and RJ Wagenet (1992) Leaching estimation and chemistry model, a process-based model of water and solute movement, transformation, plant uptake and chemical reactions in the unsaturated zone. Ver. 3. Dep. Soil Crop and Atmospheric Sci., Res. Ser.
92-3, Cornell Univ. Ithaca, NY.

Isee System (2006) Technical document for the iThink and STELLA software. http://www.iseesystems.com.

Knisel WG (1993) GLEAMS: Groundwater loading effects of agricultural management systems. UGA-CPES-BAED Pub. No. 5. U.S. Gov. Print. Office, Washington, DC.

Kookana RS, LAG Aylmore, and RG Gerritse (1992) Time dependent sorption of pesticide during transport in soils. Soil Sci. 154: 214225.

Maidment DR (1993) Handbook of Hydrology. McGraw-Hill, Inc., New York.

Mullins JA, RF Carsel, JE Scarbrough, and AM Ivery (1993) PRZM-2, a model for predicting pesticides fate in the crop root and unsaturated soil zones: User manual for release 2.0, U.S. EPA, Athens, GA.

Nearing MA, BY Liu, LM Risse, and X Zhang (1996) Curve number and green-ampt effective hydraulic conductivities. Water Resour. Bull. 32: 125-136.

Nofziger DL and AG Hornsby (1986) A microcomputer based management tool for chemical movement in soil. Apply Agric. Res. 1: 50-56.

Ouyang $Y$ and RS Mansell (1999) Potential impacts of density-driven pesticide transport upon groundwater contamination: modeling. Soil and Crop Sciences Society of Florida, Proceedings, 59: 150-159.

Ouyang Y, P Nkedi-Kizza, and RS Mansell (2003) Spatial Distribution of DDT in Sediments from Estuarine Rivers of Central Florida. J. Environ. Qual., 32: 1710-1716.

Ouyang Y, LT Ou, and GC Sigua (2005) Characterization and Spatial Distribution of Pesticide Chlordane in River Sediments. J. Environ. Qual., 34: 544-551.

Ouyang Y (2008) Modeling the Mechanisms for Uptake and Translocation of Dioxane in a Soil-Plant Ecosystem with STELLA. J. Contam. Hydrol., 95: 17-29.

Parr JF and S Smith (1973) Degradation of trifuralin under laboratory conditions and soil anaerobiosis. Soil Sci. 115: 55-63.

Peterson S and B Richmond (1996) STELLA Research Technical Documentation. High Performance Systems, Hanover, $\mathrm{NH}$.

US-EPA (U.S. Environmental Protection Agency) (1987) Health Advisory Draft Report: Paraquat. Office of Drinking Water, Washington, DC, 10-112.

Wischmeier WH and DD Smith (1978) Predicting Rainfall Erosion Losses: A Guide to Conservation Planning. Agriculture Handbook No. 537. USDA/Science and Education Administration, US. Govt. Printing Office, Washington, DC. pp. 58.

White AW Jr., LA Harper, RA Leonard, and JW Turnbull (1977) Trifluralin volatilization losses from a soybean field. J. Environ. Qual. 6: 105-110. 